\title{
Methods to Identify User Needs and Decision Mechanisms for the Adoption of Electric Vehicles
}

\author{
Axel Ensslen ${ }^{1}$, Niklas Kuehl ${ }^{1}$, Carola Stryja ${ }^{1}$, Patrick Jochem ${ }^{1}$ \\ ${ }^{1}$ Karlsruhe Service Research Institute (KSRI) at the Karlsruhe Institute of Technology, \\ Englerstrasse 11, Karlsruhe, 76131, Germany
}

\begin{abstract}
Summary
The knowledge on user acceptance for electric vehicles is of high relevance for several stakeholders in this new vehicle market. This study provides an overview of applied methods in adoption research in the field of electric vehicles. These methods comprehend (1) experimental studies and lab-experiments, (2) interviews and focus groups, (3) surveys, (4) analyses of sales documentations and (5) social media analytics. We classify the data collection methods by two dimensions - (A) sample size and (B) degree of anonymity. We provide case study results for selected methods, identify the advantages, and show how new methods may complement the traditional approaches in future research.
\end{abstract}

Keywords: Consumers, EV (electric vehicle), Germany, market, marketing

\section{Introduction}

During the last years supply and demand for all-electric vehicles (EV) has been rapidly developing [20]. The absolute numbers are, however, still low and the experiences of users with EV scarce. First users indicated already high overall satisfaction with first generation EV, but also identified some shortcomings compared to conventional internal combustion engine vehicles (ICEV). E.g. in a survey with FrenchGerman EV users they stated several advantages (such as advantageous driving characteristics, their characteristic to reduce $\mathrm{CO}_{2}$ emissions, particularly on the local level [10] and enhanced prestige perceived [8]) but also two main barriers: the limited range and high purchase prices [9]. These findings were supported by many other surveys $[4,15,35]$. The two major barriers might shrink for the new generation of $\mathrm{EV}$, which are going to have higher ranges and lower costs due to declining battery prices [33]. But, nevertheless, knowledge on user needs is still highly relevant for the automotive industry and research. Literature from different disciplines on this issue is rapidly increasing. Several methods are frequently applied but - to our knowledge - an overview including most recent methods is still missing. Therefore, we intend to shed some light into this research gap by (1) providing an overview on existing methods to identify (potential) customer needs and potential EV adoption decisions and (2) identifying research question specific advantages for each method. The structure of the paper is as follows: Section 2 provides an overview of existing methods to explore user needs regarding EV, section 3 presents case study results from a selection of the methods presented, section 4 discusses the different methodological approaches before limitations of this study are presented in section 5 and a conclusion and an outlook are provided in section 6 . 


\section{Overview on methods to explore user needs for EV}

In social sciences interviews and surveys are the most common methods to gain empirical insight in customer needs. The method of interviews is typically based on a semi-structured guideline and the interviewers follow a defined set and direction of questions while remaining free to ask more detailed questions if the interviewee shows the respective expertise [14]. As another way to collect qualitative data on specific topics, focus groups represent a special form of interviews. A focus group consists of a small number of experts who discuss a topic in a structured manner. Stated preference surveys are based on a determined set of questions often conducted ex-ante before choices were made to collect information on choice intentions for different product or service alternatives. In consequence, most frequently stated behavioral intentions are measured. But surveys can also be applied ex-post, i.e. after a decision was made in order to identify revealed preferences. Surveys have the advantage of measuring the answers provided to the questions precisely. However, the data measured can only reflect decisions from an ex-ante or ex-post point of view. They are not used to document how potential adoption decisions are taken. Analyzing sales documentations could be an option, particularly for EV stakeholders documenting their sales activities anyways. However, intimately personal factors affecting decision-making can most likely not be accounted for by this approach. Therefore, in-depth analyses of single study participants - especially for the analysis of their unconscious behaviors - are provided by laboratory experiments. With regard to the limited number of participants in a survey, interview or experiment, new forms of data collection have emerged in order to analyze several thousand data sets, e.g. through social media analytics. These methods gain insight about collective opinions and trends, but only reveal intrinsically expressed information by a certain group of people.

Frequently analyses on needs with regard to EV were based on preferences of representative samples with respondents who have predominantly never experienced EV. Hence, these analyses might not account for critical success factors of EV, as e.g. driving pleasure [10]. Asking EV users and fleet managers about their next car purchase decisions could potentially deliver better insights concerning EV specific needs and consequently the preferences during upcoming purchase decisions, as trialability of an innovation, i.e. having the possibility to experience it, is a crucial success factor for its potential adoption [37].

Based on discussions with colleagues in the EV research domain and a brief literature review on methods used to identify customer needs for EV and decision making, five major categories could be identified. These are in the following classified according to the origin of data: Data from experimental studies (cf. section 2.1), from interviews (cf. section 2.2), from surveys (cf. section 2.3), from sales documentations (cf. section 2.4) and data from social media (cf. section 2.5).

\subsection{Analysis of data from experimental studies}

According to [36] affective or hedonic attributes such as joy, pride and positive emotions influence EV purchase intentions. Weaknesses of interviews and surveys include limited explanatory power of effects. Results from these methods permit to describe certain effects but not their causes [21]. In order to draw implications about causal links of observed effects actual behavior has to be measured. Useful means for this are lab experiments. Within lab experiments, choice situations can be simulated and participant's behavior can be observed and analyzed in further detail as it would be possible based on data from interviews or surveys.

The samples used in lab experiments are mostly limited to undergraduate student samples due to practical issues and budget restrictions. The number of subjects (i.e. participants) necessary for the detection of a treatment effect depends on the effect magnitude [31]. According to [31], 'large' effects require the treatment of fewer subjects while 'small' effects are detected only in larger subject samples. Thus, for strong effects 10 to 20 subjects per treatment group are sufficient while for moderate effects 20 to 30 subjects per treatment group are recommended [31]. The central question in this research is how emotions and decision design affect EV purchase decisions. There is only little research on this topic e.g. [28, 12] but only based on survey data. The goal of the experiments proposed in this paper will be to analyze how study participants react on simulated choice tasks for different powertrain alternatives. During the experiment and choice task completion physiological data is collected. Emotional arousal manifests in physiological effects which in turn can be observed through electrodermal activity or data from electrocardiograms. The expected output is to understand the effect emotional factors such as anxiety, joy, stress, effort or arousal have on EV purchase decisions, which will help to better address these issues in real purchase situations [7, 24]. 


\subsection{Analysis of data from interviews and focus groups}

A traditional approach to identify customer needs is the interview. Depending on the scope and the conduction channel (e.g. personal or via telephone), the sample usually consists of 10 to 30 (sometimes even up to a few hundred) conversations. The interviewees can be selected either randomly or with regard to their representativeness (e.g. age and gender) [16]. As depicted above, interviews are usually characterized by a structured questionnaire with mainly open questions in order to encourage the interviewee to share deeper knowledge. This allows a flexible interview conduction since the interviewer can switch between questions if this would help to gain a common understanding of the situation and to keep the conversation fluent [3].

Another closely related approach of gathering qualitative data is the technique of focus groups. Focus groups are used to gain insight by moderating a group of experts while they are discussing a topic determined by the researcher. To our knowledge, there is no consensus in literature that clearly distinguishes focus groups from group interviews but it is said that focus groups differ in general through their formal setting, their directive interviewing and their structured question formats [30].

Interviews and focus groups with open questions are frequently analyzed by using coding techniques. Similar comments and expressions made by the interviewees are tagged with same codes to identify recurring statements and to gain a deeper understanding of the underlying needs and decision processes [26]. In our field of investigation, insights into the decision processes of vehicle purchase by private customers or institutions are focused on. By structuring the interview insights, the main influencing variables on the decision are identified and their relationship examined. The main variables identified in the interviews might provide the foundation for an experimental study design (cf. section 2.1).

\subsection{Analysis of data from surveys}

Surveys have the objective to sample individual units from a population by collecting quantitative survey data with collection techniques such as questionnaires in order to make statistical inference about a population being studied. If the subsample is chosen properly, the results can be interpreted as representative for a targeted population. This is a highly desirable property of this methodology. Methodological challenges include amongst others the identification and selection of potential sample members, contacting the sampled individuals and collecting data [17]. Survey modes include telephone, mail (post), online surveys, personal in-home surveys, personal mail or street intercept surveys and hybrids of these [27]. Decision-making for alternative fuel vehicles based on stated preference analyses has been studied profoundly during the last years. Particularly choice modelling by using surveys and discrete choice models were often applied in order to study stated preferences on alternative fuel vehicles $[2,6,18]$. Particularly the application of discrete choice methods on stated or revealed preference data from EV users and fleet managers with EV experience provide helpful insights in characterizations of potential EV adopters and their needs [9, 10, 34]. In section 3.1 results from a German case study including survey questions comparing stated relevance of different criteria for EV and ICEV purchase decisions are presented.

\subsection{Analysis of data from sales documentations}

Today, most sales departments dealing with complex products apply customer relationship management (CRM) approaches in order to improve business relationships to their customers. In these CRM systems, all contact activities with customers are documented - even if they happen with different salespersons or departments. The underlying database can be analyzed by applying data mining methods. E.g. in order to provide a basis for decision making and support the identification of sales potentials [13]. However, as global EV sales activities just started to increase during the last years [20], we could not find any published study on documented sales activities for EV. This approach could shed light on the vehicle purchase decision from a different perspective. Documented sales activities could provide in-depth insights in decision-making structures for EV adoption. Particularly sales documentations for B2B sales activities seem worth of being analyzed more profoundly [32] because commercial car purchases exceed private ones significantly. First results from a German case study are provided in section 3.2. 


\subsection{Analysis of social media data}

Apart from rather "traditional" approaches, a different - available and free - comprehensive data source comes from social media. The most popular social networking sites are Facebook and Twitter [19]. While Facebook users mostly post privately within their own friends' communities [38], micro blog data on Twitter is publicly accessible. These micro blog posts ("tweets") contain a total of 140 characters and are expressed publicly to be read, liked, shared ("retweet") or commented. Obtained data is (in general) not representative for the population; Recent studies show that people using Twitter tend to be more open than others - especially when tweeting about research and science topics [25], like e-mobility. Nonetheless, a representativeness concerning age and location is possible by filtering the metadata. The observation size can be theoretically up to 1.3 billion ${ }^{1}$.

The central question is if and how tweets can be used to automatically identify and quantify customer needs in the field of e-mobility. Therefore, a sample of tweets can be manually labelled on whether or not they contain a customer need by independent researchers. With the labelled data at hand, supervised learning algorithms are trained to identify the structure of tweet instances containing customer needs. The bestperforming model is then used on large micro blog data sets to automatically identify such "need-tweets". These needs can be extracted by either looking at the aggregated data or applying unsupervised clustering algorithms to gain knowledge on their nature and quantity. If the needs are previously known and the objective is only to quantify them, it is possible to use pre-defined "whitelists" or more complex ontologies to validate them (in the data). The expected output is a list of "top needs", based on how often they were expressed. The results have the main advantages of only considering needs that are willingly and intrinsically expressed by (possible) customers and that it is easily scalable. One disadvantage lies with the fact that only Twitter users are analyzed. Exemplary results from a first case study are provided in section 3.3.

\section{Selected case study results}

Within this section exemplary results from the methodological approaches presented in section 2 are given in order to learn about strengths and weaknesses of selected approaches. Results presented are from analyzing a set of questions collected during a survey for fleet managers of EV using organizations (section 3.1), from analysing sales documentations (section 3.2), and from analysing social media data (section 3.3).

\subsection{Analysis of data from surveys}

As an example for results from surveys we focus on vehicle purchase criteria from organizational fleet managers within this case study. In order to derive critical success factors for EV adoption in organizations a large field trial with $327 \mathrm{EV}$ in 109 organizations was carried out in the southern part of Germany. Profound information on the case study are available in [11]. 109 fleet managers, i.e. persons in organizations responsible for car purchase decisions, were interviewed between March 2014 and August 2015. All fleet managers who provided answers to the survey worked for organizations participating in the project, i.e. already took the decision to purchase EV.

The fleet managers were asked to select the most important criterion they consider first amongst 11 criteria when they took the purchase decisions for EV. Subsequently they were asked to indicate which criteria they considered afterwards. The same set of questions was asked about the criteria the fleet managers consider when making purchase decisions for ICEV. In order to test if the fleet managers' purchase decision criteria for the two drive train technologies were different, Mann-Whitney U Tests were carried out with IBM SPSS Statistics 22.

Figure 1 provides an overview on the results. The criteria of safety $(\mathrm{U}(95,87)=4,952.5 ; \mathrm{Z}=2.732$; $\mathrm{p}=.006 ; \mathrm{r}=0.20)$, car size $(\mathrm{U}(95,87)=5,499 ; \mathrm{Z}=4.083 ; \mathrm{p}<.001 ; \mathrm{r}=0.30)$ and usage costs $(\mathrm{U}(95,87)=5,282.5 ; \mathrm{Z}=3.664 ; \mathrm{p}<.001 ; \mathrm{r}=0.27)$ are involved significantly later and less frequently when deciding to purchase an EV than in purchase decisions for ICEV. Contrariwise, the design is considered earlier and more frequently. The higher importance of the criterion design $(\mathrm{U}(95,87)=3,523.5 ; \mathrm{Z}=-2.128$; $\mathrm{p}=.033 ; \mathrm{r}=-0.16$ ) could be an indication that the perception of the EV by the social environment is more

\footnotetext{
${ }^{1}$ Total users of Twitter as of 2015, c.f. http://www.businessinsider.com/twitter-monthly-active-users-2015-7?r=UK\&IR=T
} 
important. One could see it as a confirmation of the assumption, that in addition to meeting mobility requirements, EV are used for public relations purposes. Furthermore, range $(\mathrm{U}(95,87)=2,289.5 ; \mathrm{Z}=-$ $6.005 ; \mathrm{p}<.001 ; \mathrm{r}=-0.45)$ is considered earlier and more frequently during EV purchase decisions, what was expected, as EV range is still considered a major barrier restraining wide adoption. According to [5] effect sizes for the criteria safety and design are rather small. Effect sizes for car size and usage costs are medium whereas effect sizes for range are close to being strong.

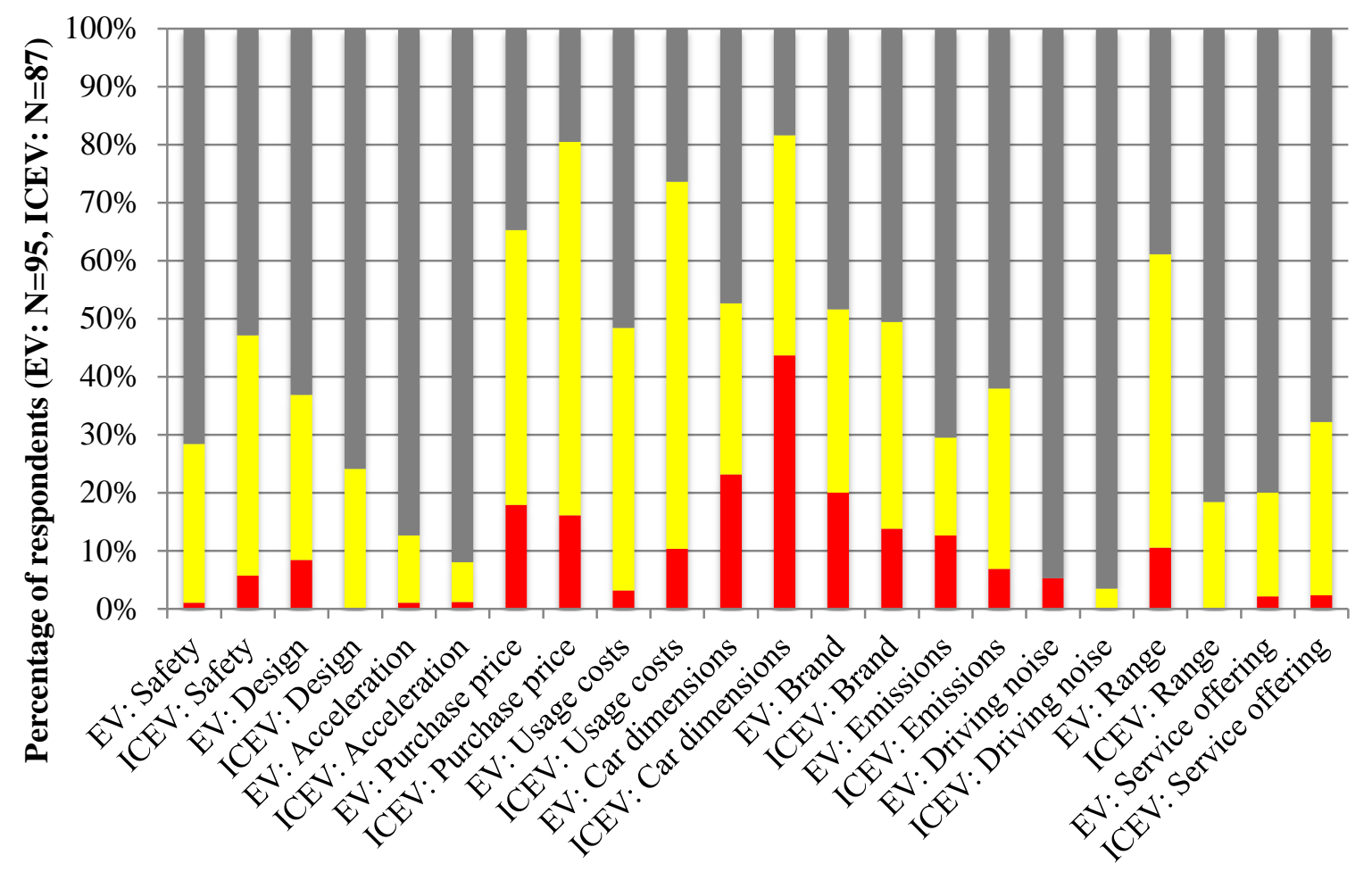

$\square$ First to decide (1 Nomination) $\quad$ Next to decide (Max. 4 Nominations) $\quad$ Unstated

Figure 1: Purchase decision criteria for EV and ICEV mentioned by the participating organizations' fleet managers

\subsection{Analysis of data from sales documentations}

During a large e-mobility field trial in Germany including 109 organizations with 327 EV sales activities were documented by the sales force. Sales did not only comprehend EV, but also additional services. These offered service bundles, "e-mobility product service systems" (PSS), include besides EV, the corresponding charging infrastructure and further connected charging services. Profound information on the case study are available in [11]. Table 1 provides an overview of the variables and their characteristics derived from the sales documentations.

The data shows that sales activities for e-mobility PSS require a substantial amount of explanatory support. After the potential project participants signed the letter of intent, on average 10 contacts between the sales force and the potential project participants were documented. Most of the contacts happened in order to exchange formalities with the potential participants and to arrange appointments and further proceedings. Furthermore, it took the organizations who signed a letter of intent on average four months until the final decision whether to participate or not was taken. As most of the interested organizations were small and medium sized enterprises with an autocratic or hierarchic organizational structure, most of them show low democratization and formalization levels. About $75 \%$ of the organizations who signed the letter of intent employ less than 160 persons. Half of the organizations have already existed 28 years ago.

In order to explain purchase decisions for e-mobility PSS offerings the variables presented in Table 1 were used as input parameters for binary logistic regression analysis. The stepwise backward Wald method was used to select statistically relevant predictors for positive e-mobility PSS purchase decisions by removing predictors not fulfilling Wald statistics requirements of $\mathrm{p}<0.1$. All 12 variables were included in the analysis. 
Table 1: Data set derived from the sales documentations of the field trial considered

\begin{tabular}{|c|c|c|c|c|c|c|c|c|}
\hline Nominal variables & $\mathbf{N}$ & \multicolumn{7}{|c|}{ Percentages } \\
\hline $\begin{array}{l}\text { Decision to participate in the field trial, i.e. decision to } \\
\text { purchase e-mobility PSS. }\end{array}$ & 229 & \multicolumn{7}{|c|}{$\begin{array}{l}\text { Positive purchase decision for PSS: } 50.22 \% \text {; } \\
\text { Negative purchase decision for PSS: } 30.57 \% \text {; } \\
\text { No decision: } 19.21 \%\end{array}$} \\
\hline$\overline{\text { Democratization level }^{2}}$ & 220 & \multicolumn{7}{|c|}{ High: $15.5 \%$ Low: $84.5 \%$} \\
\hline Formalization level $^{3}$ & 220 & \multicolumn{7}{|c|}{ High: $29.1 \%$ Low: $70.9 \%$} \\
\hline Metric variables & $\mathbf{N}$ & Min & Max & $\mathbf{M}$ & SD & $q_{0.25}$ & $q_{0.50}$ & $q_{0.75}$ \\
\hline $\begin{array}{l}\text { Duration (in days) between signing the letter of intent and } \\
\text { signing the contract to purchase the e-mobility PSS } \\
\text { offered. }\end{array}$ & 186 & 4 & 536 & 122 & 103 & 55 & 88 & 149 \\
\hline $\begin{array}{l}\text { Total number of contacts between potential participants } \\
\text { and project specific sales force. A signed contract is } \\
\text { defined as a single sales activity. }\end{array}$ & 229 & 1 & 35 & 10.21 & 5.69 & 7 & 9 & 12 \\
\hline $\begin{array}{l}\text { Number of reminder contacts: Number of contacts that } \\
\text { took place to remind the potential participant of handing } \\
\text { in missing documents. Furthermore this number counts } \\
\text { how often the sales force had to ask the contact person if } \\
\text { there is still interest to participate in the project. }\end{array}$ & 229 & 0 & 6 & 0.62 & 1.12 & 0 & 0 & 1 \\
\hline $\begin{array}{l}\text { Number of proactive contacts: This number counts how } \\
\text { often the potential participant showed to be proactive and } \\
\text { interested in participating in the project. }\end{array}$ & 229 & 0 & 3 & 0.17 & 0.46 & 0 & 0 & 0 \\
\hline $\begin{array}{l}\text { Number of contacts to persuade: Number of contacts with } \\
\text { further information sent to the organization in order to } \\
\text { persuade them from participating in the project. }\end{array}$ & 228 & 0 & 3 & 0.37 & 0.64 & 0 & 0 & 1 \\
\hline $\begin{array}{l}\text { Number of formal contacts: Formal contacts took place to } \\
\text { exchange formalities between the potential participants } \\
\text { and project partners. (e.g. distribution of documents in } \\
\text { particular offers, letter of acceptance, cancellation) }\end{array}$ & 229 & 0 & 12 & 5.03 & 2.26 & 3 & 5 & 6 \\
\hline $\begin{array}{l}\text { Number of contacts to arrange appointments and further } \\
\text { proceedings }\end{array}$ & 229 & 0 & 13 & 3.20 & 2.68 & 1 & 2 & 4 \\
\hline Number of failed contacts attempts & 229 & 0 & 9 & 0.8 & 1.49 & 0 & 0 & 1 \\
\hline Organizations' number of employees $^{4}$ & 154 & 1 & 65000 & 955 & 6003 & 14 & 51 & 155 \\
\hline Organizations' founding year $^{5}$ & 162 & 1820 & 2015 & 1979 & 35 & 1972 & 1989 & 2003 \\
\hline
\end{tabular}

Only organizations who communicated their e-mobility PSS purchase decision were included in the analysis. Therefore, results from 177 organizations could be included in the analysis. 43 of the 52 organizations not considered did not communicate their decision. Missing values for 9 of the remaining 186 organizations who communicated their decision results in the final set of 177 organizations in this analysis.

\footnotetext{
${ }^{2}$ Democratization level of an organization has to do with the number of people involved in decisions concerning fleet issues and their decision-making autonomy. A decision-making structure is considered lowly democratized when decisions are made at a single point in the organization by one or two individuals without further authorization, and highly democratized when the process involves several individuals and departments. Other indicators of lowly democratized decision-making: decision processes are initiated by only a dominating few; decision action results from proactive opportunity-seeking behaviour; solutions emphasize positive goals (rather than immediate fixes); solutions result in major departures from existing circumstances; decisions are highly integrated with the goals of the organization; and cognitive limitations prevent optimal solutions [32].

${ }^{3}$ Formalization level represents the extent to which rules and formal procedures guide the decisions concerning fleet issues. Fleets with formalized decision-making behaviour usually codify rules and procedures as written policy. At higher levels of formalization, decisions are generally initiated only in response to problems that disrupt standard operating procedures. In less formalized organizations, decisions are guided more by intuition, personal judgement, and political bargaining [32].

${ }^{4}$ Information from company profile databases

${ }^{5}$ Information from company profile databases
} 
67 organizations communicated not to be willing to purchase the e-mobility PSS offering and 110 organizations took a positive purchase decision. The method for determining the model excluded 6 variables, i.e. the total number of contacts between potential e-mobility PSS adopters and the sales force, the democratization level, the number of contacts to arrange appointments and further proceedings, the number of failed contacts attempts, the organizations' number of employees as well as the organizations' founding year. Table 2 provides an overview of the variables in the binary logistic regression model derived.

Table 2: Variables in the model

\begin{tabular}{l|c|c|c|c|c|c}
\hline & B & S.E. & Wald & df & Sig. & Exp(B) \\
\hline Duration of e-mobility PSS purchase decision & -0.012 & 0.003 & 19.360 & 1 & 0.000 & 0.988 \\
\hline Level of formalization & 0.704 & 0.417 & 2.854 & 1 & 0.091 & 2.023 \\
\hline Number of reminder contacts & 0.585 & 0.240 & 5.941 & 1 & 0.015 & 1.796 \\
\hline Number of proactive contacts & 1.040 & 0.612 & 2.886 & 1 & 0.089 & 2.830 \\
\hline Number of contacts to persuade & 0.782 & 0.340 & 5.291 & 1 & 0.021 & 2.186 \\
\hline Number of formal contacts & 0.165 & 0.091 & 3.255 & 1 & 0.071 & 1.179 \\
\hline Constant & 0.122 & 0.544 & 0.051 & 1 & 0.822 & 1.130 \\
\hline
\end{tabular}

The probability of organizations for positive e-mobility PSS purchase decisions decrease significantly with increasing duration of the decision making process. On the other hand probabilities for positive e-mobility PSS purchase decisions increase with an increasing level of formalization in the organizations, with an increasing number of contacts, i.e. reminder contacts, proactive contacts, contacts to persuade as well as formal contacts. Multi-collinearities could not be observed, as all correlations between dependent variables are inferior to 0.8 [29]. The model summary indicates that the overall quality is acceptable $(-2 \log$ likelihood: 187.4; Cox and Snell R Square: 0.24; Nagelkerke R Square: 0.32). Therefore our results show that an acceptable part of the variations observed concerning e-mobility PSS adoption decisions can be explained by variables derived from underlying textual sales documentations.

The results show that sales activities for e-mobility PSS require high amounts of consultancy and take very long, although monetary incentives were provided in order to make quick decisions. As the field experiment proves that e-mobility PSS co-creating value in service networks between charge point operators and EV users could be allocated successfully in 109 organizations, we recommend to couple monetary incentives to e-mobility PSS adopting organizations contributing actively to service networks intending to overcome EV specific barriers as the lack of accessible charging infrastructure and range anxiety. Furthermore, we recommend e-mobility PSS selling organizations to create e-mobility PSS offers which are customer-oriented, i.e. useful and easy to understand. Attempts to reduce complexity might be fruitful. Considering that public relations purposes are currently a driving factor for successful e-mobility PSS sales activities (section 3.1), services explicitly supporting this goal of e-mobility PSS adopting organizations might create additional value.

\subsection{Analysis of social media data}

A first study showed that in a set of 600k retrieved e-mobility-specific tweets, $2.4 \mathrm{k}$ have high potential concerning needs directly expressed by users for Germany (disregarding bots, news, ads) [22]. The data set was received between March and August 2015 by recording all German-speaking tweets that contained one of 33 e-mobility-specific key words ${ }^{6}$ via the Twitter Streaming API. The $2.4 \mathrm{k}$ potentially interesting tweets were labelled by 35 paid individuals on whether or not they contain a need. With this data at hand, Machine Learning algorithms can be trained to automatically detect tweets that contain customer needs in the future, which is part of ongoing research [23] beyond this paper.

Out of the $2.4 \mathrm{k}$ tweets, there was a consensus between labelers on 330 tweets expressing needs. The remaining data were either tweets not containing a need or tweets with disagreements [23]. Of those 330 "need-tweets", 60 were cost-related, 60 car-related, 162 charging-related and 28 about individual and social needs (Figure 2). Other references were specific and could not be related to any of the four mentioned

\footnotetext{
${ }^{6}$ Keywords (alphabetical, case-insensitive): bmw i3; e-tankstelle; eauto; ecar; egolf; electric mobility; electric vehicle; elektroauto; elektrofahrzeug; elektromobilitaet; elektromobilität; e-mobility; emobility; eup; fortwo electric drive; ladesaeule; ladesäule; miev; nissan leaf; opel ampera; peugeot ion; renault zoe; tesla model s.
} 
categories. Concerning the cost-related tweets, most users were dissatisfied with the current retail prices of EV. Regarding the car-related tweets, users mostly expressed needs about certain features of the car, like battery size or visual appearance. The largest share in "need-tweets" is charging-related, where users were dissatisfied with the (missing) charging infrastructure or inconveniences of the charging process. The 28 remaining tweets mostly concerned ecological or social needs related to EV. Although this result is not representative, we intend to provide additional insights on customer needs for the German market based on Twitter data. The majority of needs expressed were charging-related.

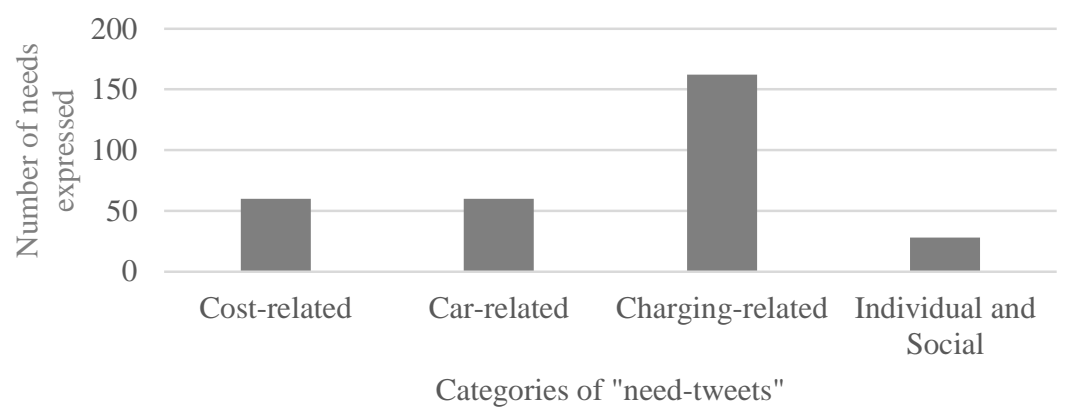

Figure 2: Number of "need-tweets" labelled by 35 individuals (only regarding tweets with consensus, $\mathrm{n}=330$ )

\section{Discussion and recommendations}

Each of the methods explained in section 2 has its strengths and weaknesses. The scope of this section is to propose suitable application scenarios for the different methods studied.

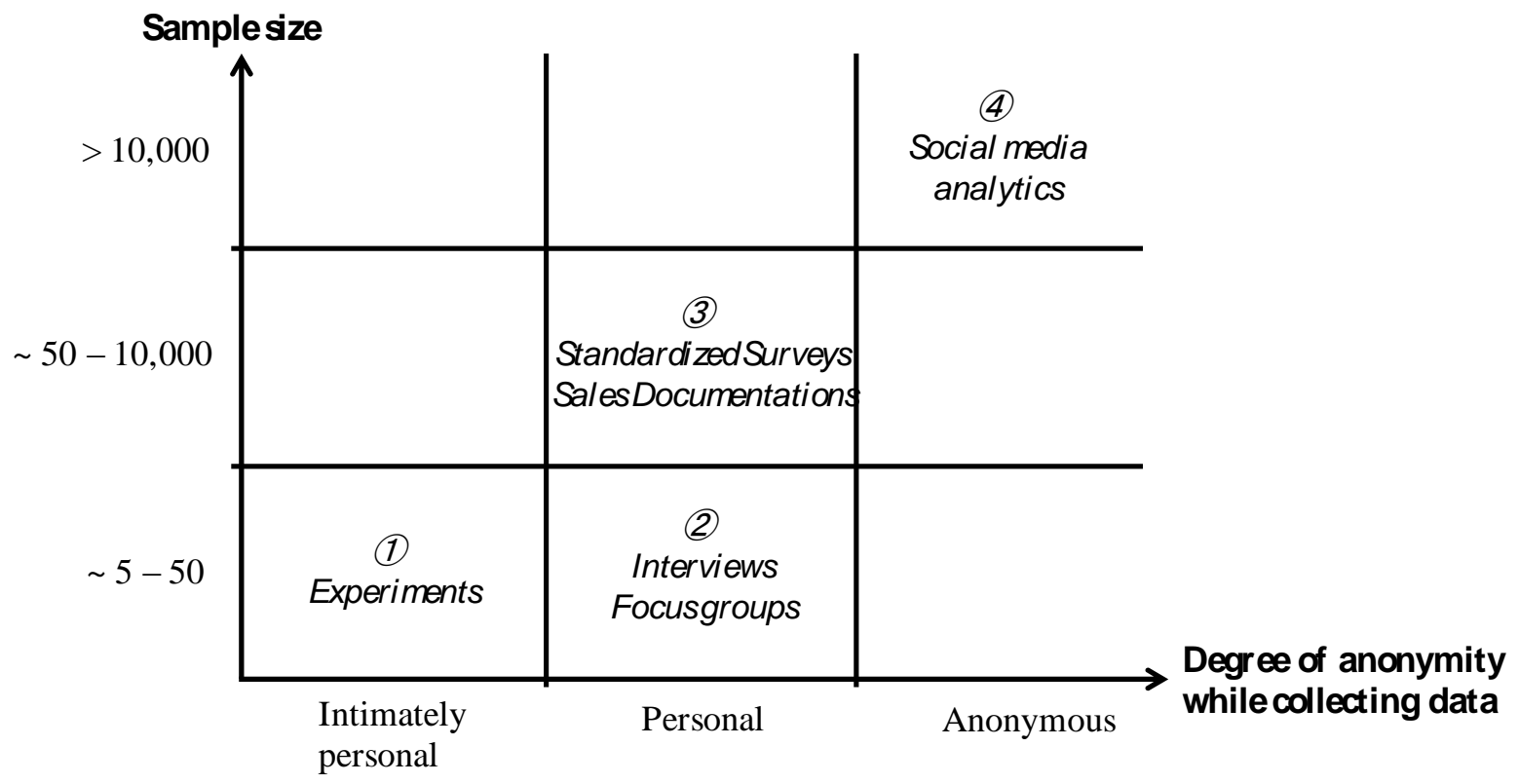

Figure 3: Data collection methods to identify users' needs and decision mechanisms for the adoption of EV

In order to illustrate possible application scenarios and to give recommendations about method suitability, two dimensions were used as reference points: (1) available sample size (from one person to millions) and (2) degree of ensured anonymity during data collection (from intimately personal to anonymous). Based on those dimensions, four clusters emerged from the analysis (Figure 3).

The first cluster comprises the conduction of experiments and is preferred for small samples since each of the study participants has to be prepared and observed individually, for example by the use of biosensor technologies (amongst others). Experimental studies provide the basis for observing behavioral traits of participants and for collecting physiological measures including indicators for emotional arousal during 
simulated decision situations. In the context of decision behavior analysis, this approach allows to analyze the influence of emotions on EV adoption decisions.

The second cluster includes the qualitative social research methods of interviews and focus groups comprising data collected on a personal level. These two methods can be used to explore needs when requirements for new products and services are still diffuse and ideas and concepts need to be developed. Furthermore, qualitative methods are also applied when sample sizes of persons who had possibilities to test innovations are too small for using quantitative methods.

Data from the third cluster either originate from conversations (e.g. sales documentations) or is collected in surveys. Stated preference surveys provide the basis to check hypotheses frequently generated in qualitative pre-studies. Stated preference surveys are usually conducted within a certain context that might be more or less constructive in order to provide an answer to the research question considered. For example, asking persons who have not made any experiences with $\mathrm{EV}$ about their preferences might be biased, as EV specific needs cannot be known at first hand by persons who never used an EV. Another example concerns analyses of the decision making process for e-mobility PSS. Asking EV users, who were not involved in emobility PSS purchase decisions on this decision process might be biased, too. On the other hand, using surveys to address research questions concerning subjective experiences of fleet managers and decision makers during their e-mobility PSS decision-making processes might deliver interesting results, particularly concerning subjective perceptions. In all cases the researchers interact with the study participants, i.e. the study participants know that they contribute to research activities. Surveys, focus groups and guided interviews are well established in the research community and have been broadly used in EV adoption studies.

Concerning white spots in empirical research, we identified a lack of studies analyzing revealed preferences, i.e. studies based on objective data documenting EV adopters' e-mobility PSS adoption decisions from sales forces point of view. Our analyses of documented sales activities for e-mobility PSS intended to close this gap. We therefore analyzed sales documentations of e-mobility PSS originating from an e-mobility project in the southern part of Germany. Insights into procurement decisions of e-mobility PSS could be provided although the process of decision-making remained hidden. Certain performance indicators during the decision-making process provided information on success potentials concerning emobility PSS sales activities.

The fourth cluster includes methodological approaches analyzing social media data. These methods should be preferably used if huge data sets of many (potential) users are required and results are needed quickly. As it can be applied in real-time and no man-power is required, it is well-suited to identify trends. Innovative applications might be possible, e.g. analyses of effectiveness of political measures being tested and investigated in real-time. As only already available data published on social media platforms are used, the collection of data is mostly anonymous. Furthermore, only aggregated data seem of interest when macroeconomic trends are analyzed.

To the best of our knowledge there have been neither studies available analyzing EV adoption decision mechanisms during choice experiments coupled with physiological measures for emotions, nor any published studies analyzing e-mobility PSS adoption decisions of organizations based on sales documentations, nor studies analyzing trends concerning potential EV users' needs based on data from social media. Therefore, the work presented in this article significantly increases the methodological approaches used in e-mobility market research activities. We propose that results from traditional methods might be supported by the results from other methodological approaches in order to increase their reliability.

\section{Limitations}

We do not claim to cover the complete set of methods available, i.e. our listed five methods only represent a subsample of methods to identify customer needs. E.g. Design Thinking [1] is not considered in this study.

The experimental studies planned face several challenges. First of all, the currently targeted samples focusing on local students cause severe sample biases, as they might not have any experiences with EV and might not have been involved in EV purchase decisions so far. Furthermore, real EV purchase scenarios are difficult to simulate due to budget restrictions for the planned experiments. Simulating EV adoption scenarios by consideration of rental scenarios might be a less cost intensive alternative. 
Concerning the case study results analyzing survey data and sales documentations it needs to be critically mentioned that project specific e-mobility PSS could only be successfully allocated due to the monetary incentives provided to the organizations for taking part in the field experiment with a contractual obligation to acquire an EV, project specific connected charging infrastructure and corresponding connected charging services [11]. Organizations willing to participate were incentivized to take the decision as quickly as possible, as the monetary incentives were provided for each month the organizations were participating in the project, which lasted until the end of 2015. Furthermore, the sample is not representative for the German organizations as the sectors manufacturing, information and communication and public administration are overrepresented whereas the sectors wholesale and trade and other service activities are underrepresented. However, the sample might be representative for EV adopting organizations in the southern part of Germany (Baden-Württemberg) in the year 2014. As documentations for e-mobility PSS sales activities are only available for organizations who signed a letter of intent at sales events for emobility PSS, information on organizations that were generally interested, but did not sign the letter of intent, are missing and not considered in our analyses.

Concerning the analysis of social media, filtering "the nuggets" from the huge amount of textual data sets available as well as fully automating their treatment including machine learning methods remain challenging tasks.

\section{Conclusions and Outlook}

The knowledge on user acceptance for electric vehicles might influence the mid-term market potentials of electric vehicles considerably. Hence, electric vehicle providers have a significant interest in this information. We developed an overview of applied methods in adoption research in the field of electric vehicles. These methods comprehend (1) experimental studies and lab-experiments, (2) interviews and focus groups, (3) surveys, (4) analyses of sales documentations, and (5) social media analytics. Furthermore, we classified the methods by two dimensions: (A) sample size and (B) degree of anonymity. We identified the advantages of each methodology and showed how the new methods may complement the traditional approaches in future research and provided selected results for some methods.

Even though our overview is not complete, the general recommendations persist. There is no unambiguous suggestion, but general assistance: While user needs of products in the very early market phase might be better analyzed by experiments or interviews and focus groups, the user needs of already established products might be better and analyzed by data from representative surveys. The results might be supported by insights from sales documentation and social media data analysis. Social media analyses can support in exploring trends, quantifying needs and offers the possibility to work with real-time-data. We showed that the analysis of sales documentation can reveal promising insights on customer needs. Therefore, we encourage e-mobility service providers to permit scientists further access to selected sales data in the future.

Future research might improve algorithms for analyzing sales documentations and data from social media. It might be worth to develop algorithms automatically structuring sales documentations and social media data by automating data extraction and improving statistical modelling by applying business analytics and machine learning methods. This could be beneficial to better support sales activities for e-mobility product service systems in the future. Social media analytics could be a promising tool in supporting the detection of new challenges in e-mobility.

\section{Acknowledgments}

This paper has been written in the context of the research projects DELFIN, Get eReady and the Profilregion Mobilitätssysteme Karlsruhe. The DELFIN project is funded by the German Federal Ministry of Education and Research $(B M B F)$ under the promotion sign 01FE13002. The Get eReady project is funded by the German Federal Ministery of Economics and Energy (BMWI) under the promotion sign 16SBW020E. The Profilregion Mobilitätssysteme Karlsruhe is funded by the Ministry of Science, Research and the Arts Baden-Württemberg (MWK). We also thank the project management agency German Aerospace Center $(P T-D L R)$ for the project support. 


\section{References}

[1] Brown, T., 2008. Design Thinking. Harvard Business Review. S. 84-92.

[2] Brownstone, D., Bunch, D. S., Train, K. E., 2000. Joint mixed logit models of stated and revealed preferences for alternative-fuel vehicles. Transportation Res. Part B: Methodological 34(5),315-338.

[3] Bryman, A.; Bell, E., 2011: Business Research Methods. New York: Oxford University press.

[4] Bühler, F., Cocron, P., Neumann, I., Franke, T., Krems, J. F., 2014. Is EV experience related to EV acceptance? Results from a German field study. Transportation Research Part F 25, 34-49.

[5] Cohen, J., 1992. A power primer. Psychological Bulletin, 112, 155-159.

[6] Daziano, R. A., Achtnicht, M., 2014. Forecasting Adoption of Ultra-Low-Emission Vehicles Using Bayes Estimates of a Multinomial Probit Model and the GHK Simulator. Transportation Science 4, 671-683.

[7] Desmet, P. M., Hekkert, P., Jacobs, J. J., 2000. When a car makes you smile. Advances in consumer research 27, 111-117.

[8] Ensslen, A., Jochem, P., Fichtner, W., 2013. Experiences of EV Users in the French-German Context, Proceedings of EVS27-Conference, Barcelona, Spain.

[9] Ensslen, A., Jochem, P., Rometsch, M., Fichtner, W., 2016. Adoption of EV in the French-German context. In: Schäuble, J., Jochem, P., Fichtner, W., 2016. Cross-border Mobility for Electric Vehicles. KIT Scientific Publishing.

[10] Ensslen, A., Paetz, A.-G., Babrowski, S., Jochem, P., Fichtner, W., 2015. On the road to an electric mobility mass market - How can early adopters be characterized?. In: Working Paper Series in Production and Energy, No. 8, ISSN: 2196-7296.

[11] Ensslen, A., Gnann, T., Globisch, J., Plötz, P., Jochem, P., Fichtner, W., 2016. Willingness to Pay for EMobility Services: A Case Study from Germany. In KSS 2016 Proceedings. Karlsruhe.

[12] Franke, T., Neumann, I., Bühler, F., Cocron, P., and Krems, J. F., 2012. Experiencing Range in an Electric Vehicle: Understanding Psychological Barriers. Applied Psychology 61(3), 368-391.

[13] Gerecke, U. Customer Relationship Management, 2001. Controlling 13 (4-5), 235-242.

[14] Gläser, J., Laudel, G., 2010. Experteninterviews und qualitative Inhaltsanalyse. Wiesbaden: SpringerVerlag.

[15] Gnann, T., Plötz, P., Kühn, A., Wietschel, M., 2015. Modelling market diffusion of electric vehicles with real world driving data - German market and policy options. Transportation Research Part A 77, 95-112.

[16] Griffin, A., Hauser J. R. 1993. The voice of the customer. Marketing science 12 (1), 1-27.

[17] Groves, R.M., Fowler, F. J., Couper, M.P., Lepkowski, J.M., Singer, E., Tourangeau, R., 2009. Survey Methodology. New Jersey: John Wiley \& Sons.

[18] Hidrue, M. K., Parsons, G. R., Kempton, W., Gardner, M. P., 2011. Willingness to pay for electric vehicles and their attributes. Resource and Energy Economics 33 (3), 686-705.

[19] Hughes, D. J., Rowe, M., Batey, M. and Lee, A., 2012. A tale of two sites:Twitter vs. Facebook and the personality predictors of social media usage. Computers in Human Behavior 28 (2), pp. 561-569.

[20] IAE - International Energy Agency (2013). Global EV Outlook. https://www.iea.org/publications/freepublications/publication/GlobalEVOutlook_2013.pdf, accessed on 2016-03-10.

[21] Kantowitz, B. H., Roediger III, H. L., and Elmes, D. G., 2005. Experimental Psychology - Understanding Psychological Research. Stamford: Wadsworth Thomson Learning, 8 edition.

[22] Kuehl, N., Scheurenbrand, J., Satzger, G., 2016. "Needs from Tweets": Towards Deriving Customer Needs From Micro Blog Data. Multikonferenz Wirtschaftsinformatik (MKWI), Illmenau, Germany.

[23] Kuehl, N., Scheurenbrand, J., Satzger, G., 2016. Needmining: Identifying customer needs in micro blog data, KSRI Discussion Paper, Karlsruhe, Germany.

[24] Luce, M. F., 1998. "Choosing to Avoid: Coping with Negatively Emotion-laden Consumer Decisions". Journal of Consumer Research 24(4), 409-433. 
[25] Marshall, T. C., Lefringhausen, K., Ferenczi, N., 2015. The Big Five, self-esteem, and narcissism as predictors of the topics people write about in Facebook status updates. Personality and Individual Differences 85, 35-40.

[26] Mayring, P., 2007. Qualitative Inhaltsanalyse. Grundlagen und Techniken. Weinheim.

[27] Mellenbergh, G.J., 2008. Surveys. In H.J. Adèr \& G.J. Mellenbergh (Eds.) (with contributions by D.J. Hand), Advising on Research Methods: A consultant's companion. Huizen, Netherlands: Johannes van Kessel Publishing.

[28] Moons, I. and De Pelsmacker, P., 2012. Emotions as determinants of electric car usage intention. Journal of Marketing Management, 28(3-4):195-237.

[29] Menard, S., 1995. Applied Logistic Regression Analysis. Thousand Oaks: Sage.

[30] Morgan, D. L., 1996. Focus groups. Annual review of sociology, 129-152.

[31] Myers, D., 2004. Psychology. New York: Worth Publishers, 7 edition.

[32] Nesbitt, K., Sperling, D., 2000. Myths regarding alternative fuel vehicle demand by light-duty vehicle fleets. Transportation Research Part D: Transport and Environment 3(4), 259-269.

[33] Nykvist, B., Nilsson, M., 2015. Rapidly falling costs of battery packs for electric vehicles. Nature Climate Change 5, 329-332.

[34] Plötz, P.; Schneider, U.; Globisch, J.; Dütschke, E., 2014. Who will buy electric vehicles? Identifying early adopters in Germany. Elsevier Transportation Research Part A 67, 96-109.

[35] Propfe, B., Kreyenberg, D., Wind, J., Schmid, S., 2013. Market penetration analysis of electric vehicles in the German passenger car market towards 2030. International Journal of Hydrogen Energy 38(13), 52015208 .

[36] Rezvani, Z., Jansson, J., Bodin, J., 2015. Advances in consumer electric vehicle adoption research: A review and research agenda. Transportation Research Part D 34, 122-136.

[37] Rogers, E. M., 2003. Diffusion of Innovations. New York.

[38] Wilson, R. E., Gosling, S. D., Graham, L. T., 2012. A Review of Facebook Research in the Social Sciences. Perspectives of Social Sciences 7 (3), 203-220.

\section{Authors}

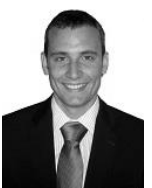

Axel Ensslen is research assistant at the French-German Institute for Environmental Research and member of the research group Transport and Energy at the Chair of Energy Economics since 2011. He studied industrial engineering at the Karlsruhe Institute of Technology (KIT), Germany and the Ecole Nationale Supérieure des Mines de Nancy (ENSMN), France. His research activities focus on socioeconomic aspects of electric mobility.

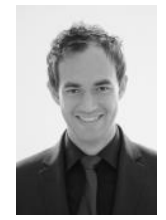

Niklas Kuehl is a research assistant at the Karlsruhe Service Research Institute (KSRI) and the Institute of Applied Informatics and Formal Description Methods (AIFB). He studied industrial engineering at the Karlsruhe Institute of Technology (KIT). His research activities focus on the application of analytical machine learning approaches to identify customer needs.

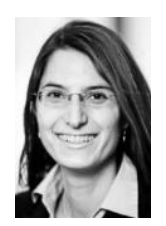

Carola Stryja is research assistant at the Karlsruhe Service Research Institute (KSRI). She studied industrial engineering at the Karlsruhe Institute of Technology (KIT). Her research focuses on behavioral economics and their application in the domain of electric mobility.

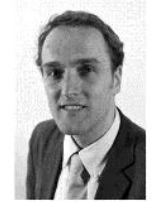

Patrick Jochem is research group leader at the KIT-IIP, -DFIU, -KSRI, and chair of energy economics. In 2009 he received his $\mathrm{PhD}$ in transport economics form KIT. He studied economics at the universities in Bayreuth, Mannheim and Heidelberg, Germany. His research interests are in the fields of electric mobility and ecological economics. 